\title{
"Proof of Life":
}

\section{Restoration and Old-Car Patina}

\author{
David N. Lucsko
}

In November 1986, Victor Ofner of Escondido, California, took delivery of a worn-out German-market VW. Delivered in Mannheim in the autumn of 1953, the grey-blue Beetle had plied the streets of the Federal Republic for twenty-six years before being placed in storage. There it sat until a friend of Ofner's found it and helped arrange its purchase and shipment to the US. After taking delivery of the inoperable but largely original car, Ofner spent the next eight-and-a-half years of his spare time on a thorough restoration. He rebuilt the engine and transmission, completed the bodywork, applied the paint, powder-coated the chassis, cad-plated every nut and bolt, and spent countless hours hunting for period-correct accessories. The outcome was flawless. The car took "best of show" when it debuted at a vintage meet in 1995, and in 1996 it was featured in Hot $V W s$. Ofner "outdid himself with this restoration", the magazine gushed, for his car was "now better than when it rolled off the factory assembly line". ${ }^{1}$

Ofner's results were exceptional, but his goals and methods certainly weren't. For many decades, from its modest origins in the interwar years to its heyday as a multifaceted mass phenomenon in the 1970s-1990s, the hobby of old-car restoration was largely predicated upon a widely-shared aim: like-new form. This goal was also shared by others in the broader old-car world: museums, high-end private collections, auction houses, insurance firms and the like. With the important exception of museum specialists, however, this essay focuses specifically on the like-new mantra as it played out among old-car hobbyists, the largely do-it-yourself crowd of middle-income gearheads who restore, drive and

1 Smith, Robert K.: “Above-Standard Standard”, in: Hot VWs (HVW), Aug. 1996, p. $40-43$, here p. 43. 
show old cars in their spare time. ${ }^{2}$ This is certainly not to suggest that these enthusiasts have always agreed on what exactly "like-new" means - or, by extension, what a "restoration" actually entails. Does it require a strict adherence to factory specifications, or are some modifications acceptable? Should drivability or durability be factored in? Should a car be rebuilt to the highest possible standard, like Ofner's Beetle, or should one aim instead to replicate the typically more modest standards of factory fit and finish? Finally, which cars ought to be restored - only high-end makes? Only rare examples? Only those of a certain age?

On these and other points, disagreement has long been rife. Yet across time, space and its many niches and sub-niches, the hobby of old-car restoration entailed at the very least an effort to erase all signs of wear and tear. Many never quite finished the job, of course, and "work-in-progress" cars have always been common at shows, accompanied by a litany of explanations with which every old-car nut could sympathise: "I hope to get it painted this autumn", "I'm still looking for the correct tail lights", "I might have finally found the right material for the seats". In short, not every restored car was actually perfect, but perfection was the aim.

By the early 2000s, however, a curious twist was in the making. Evident at old-car shows and in magazines and online forums, this was the appearance of "restored" cars that weren't pristine. "Yes, it is cool", a popular sticker associated with this trend read, and "No, I'm not going to paint it". ${ }^{3}$ Unlike the "workin-progress" cars of prior decades, these examples, complete with faded paint, patches of rust and worn and stained upholstery, were considered finished. Carefully rebuilt to run and drive like new, or often better than new, without obliterating the visible marks and scars of their many years of service, these "patina rides" quickly nudged their way onto the old-car scene. To be fair, outliers - historically-significant vehicles in very rough condition, as well as unrestored

2 A number of synonyms for "old-car hobbyist" are in common use, including "old-car gearheads", "restoration enthusiasts", "old-car restoration enthusiasts", "old-car enthusiasts", "classic-car enthusiasts", and the like. I use these terms interchangeably in this essay. On the demographics of the old-car hobby, see Lucsko, David N.: The Business of Speed: The Hot Rod Industry in America, 1915-1990, Baltimore: Johns Hopkins University Press 2008, p. 224-226; Id.: Junkyards, Gearheads, and Rust: Salvaging the Automotive Past, Baltimore: Johns Hopkins University Press 2016, chs. 2 and 4; Cross, Gary S.: Machines of Youth: America's Car Obsession, Chicago: University of Chicago Press 2018, ch. 8.

3 These have been available for years; see, for example, vintagevolks: advertisement, https://www.thesamba.com/vw/classifieds/detail.php?id=2103221 (accessed 13.08.2018). 
"survivors" in good, if not pristine form - had long been part of the hobby. ${ }^{4}$ What was genuinely new in the early twenty-first century was the extent to which patina had transfixed the old-car world.

This paper investigates this trend. Following a brief terminological discussion, it begins with a survey of the history of old-car restoration, focusing specifically on hobbyists. ${ }^{5}$ Then, drawing heavily on broadly-circulated periodicals (including Motor Trend, Cars and Parts, Hot Rod and Hot VWs) and, for a more bottom-up angle on recent developments, important international forums like thesamba.com, it seeks out the origins of what I call the "patination turn" before ending with a discussion of its broader significance. For as we will see, beneath

4 On survivors and other outliers, see for example Dieter, R. E./Duerksen, Menno: "Tool Bag", in: Cars and Parts (C\&P), Feb. 1972, p. 91; Unrestored Antique Auto Club of America: advertisement, in: C\&P, Jun. 1974, p. 113; Bertilsson, Bo: "Super Type II x 2!", in: VW Trends (VWT), Jul. 1992, p. 78-79; Strohl, Daniel: "Historically Rich", in: Hemmings Classic Car, Dec. 2005, p. 58-63; RM Auctions: advertisement, in: Hemmings, Nov. 2007, p. 608; Anon.: "Wrecked Bugatti to Aid Charity", in: Detroit Free Press, 28 Jan. 2010, n. p.; Anon.: "HRG Returns to Family Fold", in: Classic and Sports Car (C\&SC), Nov. 2010, p. 28; Anon.: "Best of 2010", in: C\&SC, Feb. 2011, p. 12. There were also those among the old-car crowd who preferred rough-looking and rough-running cars, especially urbanites like Car and Driver's Warren Weith; see for example Anon.: "Cars", in: Car and Driver (C\&D), Mar. 1965, p. 20 and 22.

5 The literature on automotive restoration as a leisure-time activity is nearly nonexistent; exceptions include Lucsko, Junkyards, chs. 2 and 4, and Cross, Machines of Youth, ch. 8. The literature on automotive subcultures and enthusiasm more broadly is better developed; in addition to the titles cited above, see Dannefer, Dale: "Neither Socialization nor Recruitment: The Avocational Careers of Old-Car Enthusiasts", in: Social Forces 60 (1981), p. 395-413; Moorhouse, H. F.: Driving Ambitions: A Social Analysis of the American Hot Rod Enthusiasm, Manchester: Manchester University Press 1991; Post, Robert C.: High Performance: The Culture and Technology of Drag Racing, 1950-1990, Baltimore: Johns Hopkins University Press 1994; Bright, Brenda Jo: Mexican American Low Riders: An Anthropological Approach to Popular Culture, PhD thesis: Houston/Texas, Rice University 1994; Id.: Customized: Art Inspired by Hot Rods, Low Riders, and American Car Culture, New York: Harry N. Abrams 2000; DeWitt, John: Cool Cars, High Art: The Rise of Kustom Kulture, Jackson: University Press of Mississippi 2002; Lucsko, Business of Speed; Jakle, John A./Sculle, Keith A.: Motoring: The Highway Experience in America, Athens: University of Georgia Press 2008, p. 4 and 225-226; Kinney, Jeremy: "Racing on Runways: The Strategic Air Command and Sports Car Racing in the 1950s", in: ICON 19 (2013), p. 193-215. 
its palpable sense of nostalgia and its outward obsession with the obsolete, the old-car hobby has actually long been predicated upon a very real reverence for novelty and progress. Only with the patination turn did a genuine sense of history - real, lived, weather-worn history - finally come to the fore.

\section{REPAIR AND RESTORATION}

What exactly do we mean by "restoration"? In his recent book Together (2012), Richard Sennett describes "restoration", "remediation" and "reconfiguration" as distinct forms of "repair". Restoration describes a repair in which one seeks to return a broken object to its original condition, ideally without leaving any traces of one's work behind. Remediation, on the other hand, is a form of repair in which one retains an object's original form and function while incorporating new or improved materials. Reconfiguration, the most radical of Sennett's three Rs, involves a thorough reconceptualisation of an object's form and function. ${ }^{6}$

Sennett's insights here are useful, and I will return to them later in this essay. But his terminology is slightly problematic, because in the automotive world both restoration and repair already carry meanings that are incongruent with his framework. To wit, when a part or system on a running car breaks down, you repair it. ${ }^{7}$ When a more thoroughgoing overhaul to multiple systems is required, as is typical for a worn-out car or one that sat unused for a number of years, you restore it. A recent treatise on automotive preservation from the Fédération Internationale des Véhicules Anciens (FIVA, a global coalition of old-car clubs) seeks in part to clarify this distinction. Repair, according to its Charter of Turin (2013), is work done when a car is still in normal use, and "involves the adaptation, refurbishment or replacement of existing, damaged or missing components" in order to "make a vehicle fully operational again". This includes both "pragmatic repairs" (also known among old-car hobbyists as "bodge jobs": makeshift fixes, often using improvised materials, made to quickly return a vehicle to

6 Sennett, Richard: Together: The Rituals, Pleasures, and Politics of Cooperation, New Haven: Yale University Press 2012, p. 212-215; see also id.: The Craftsman, New Haven: Yale University Press 2008, p. 199-202.

7 On repair, see Borg, Kevin L.: Auto Mechanics: Technology and Expertise in Twentieth-Century America, Baltimore: Johns Hopkins University Press 2007; Pirsig, Robert M.: Zen and the Art of Motorcycle Maintenance: An Inquiry into Values, New York: William Morrow 1974; Harper, Douglas: Working Knowledge: Skill and Community in a Small Shop, Berkeley: University of California Press 1987. 
service), as well as more careful "professional repairs" (the sorts of jobs done by skilled mechanics at a garage). ${ }^{8}$ Restoration, on the other hand, involves the same kinds of tasks often seen in professional repairs but is done later, "with the aim of displaying the vehicle as it was at a particular point in time". ${ }^{9}$ In other words, restoration brings together multiple kinds of repair work in order to return a vehicle to some prior state - typically, in practice, its state when showroom-new. Thus, while Sennett's conceptualisation of "restoration" as a form of "repair" makes some sense in theory, the terms are never used that way in practice. One would never call for help from the side of the road and tell the person who answers that one's car requires "restoration". That would be like going in for a routine dental cleaning and calling it "mandibular surgery". Likewise, one would never drag a beat-up car with a rusted-out body, shredded interior and seized mechanicals to a garage and simply say it needs "repairing". That would be like asking for a bit of floss to deal with a fractured jaw.

In sum, "repair", in real-world use, refers to the act of addressing a specific malady on a car, while "restoration" describes the much more comprehensive process of returning one to like-new form. Such has been the case for many decades. Well before the mass production of the Model $\mathrm{T}$ began, as Kevin Borg has shown, wealthy early adopters either worked on their cars themselves or hired chauffeurs both to drive them around and to care for their machines. And, as Borg's sources clearly show, the work that they performed was called "repair" (or, as a verb, "repairing" or "fixing"). Garages where owners stored their vehicles had "space devoted to repair of cars", workshops that catered to early motorists billed themselves as "repairing" centres, and schools offering training in all things automotive portrayed their programmes as "complete driving and repair course[s]". ${ }^{10}$ Although the work was often more involved and much more

8 Fédération Internationale des Véhicules Anciens (FIVA): Charter of Turin, 2013, reprinted in FIVA: Charter of Turin Handbook, Brussels: FIVA 2017, p. 19-21, here p. 19.

9 FIVA, Charter of Turin, p. 19-21, here p. 20. Further discussion of the Charter of Turin appears later in this essay.

10 Borg, Auto Mechanics, quoted text from fig. 6, 7, 12 and 18. In addition to "repair", other terms crept into use over time - "maintenance", "lubrication", "service" - but these typically referred to various forms of preventive care, much more so than repair. For some examples, see Borg, Auto Mechanics, fig. 25: Witzel, Michael Karl: The American Gas Station: History and Folklore of the Gas Station in American Car Culture, Osceola, Wisconsin: Motorbooks International 1992: Jakle, John A./Sculle, Keith A.: The Gas Station in America, Baltimore: Johns Hopkins University Press 1994. 
frequently required than would be the case in later years, it was certainly "repair" in the modern sense: discreet operations performed to address specific faults on otherwise roadworthy cars. Likewise, "restoration" has been the chief term used by old-car hobbyists to describe the process of returning a car to likenew form since at least the early 1950s, when it largely eclipsed the earlier and not entirely synonymous "refurbishment" (discussed in the subsequent section). ${ }^{11}$ Stable across time, these common definitions make it difficult to lean on Sennett's terminology when studying the old-car hobby.

Further complicating matters is the fact that "restoration", in the automotive world, covers an array of activities mapping partly onto what Sennett calls "restoration", and partly onto what he calls "remediation". This is due to the broad range of opinion, mentioned earlier, regarding the meaning of "like-new" - regarding, that is, the precise ends towards which one should labour when engaged in automotive restoration. To those for whom the like-new standard means "perfectly original" - i. e., precisely as a car looked and performed when it left the

11 Feature articles on the growing old-car hobby began to appear in the early 1950s (when the enthusiast magazine itself was still a new genre, having first appeared in the US in 1947 [see Lucsko, Junkyards, p. 249-250]). Among the first sixteen feature stories and letters to the editor on the post-war hobby I have come across in my research thus far, all published between 1951 and 1957, "restore", "restored" or "restoration", deployed in the common-use manner I describe here, appeared in all of them, whereas "refurbish" or "refurbishment" are found in only three, the last of which appeared in 1954. On restoration, see Stratton, Charles L.: "Museum in the Rough", in: Motorsport, Aug. 1952, p. 31 and 48-49; Gottlieb, Robert J.: "Classic Comments", in: Motor Trend (MT), Oct. 1952, p. 36-37 and 55; Jaderquist, Eugene: "The Classic Thrill of Yesteryear", in: True's Automotive Yearbook (1952), p. 2-7 and 100-102; Gottlieb, Robert J.: "Classic Comments", in: MT, Feb. 1953, p. 54-57; Cetin, Frank: "He Brings 'Em Back to Life", in: Cars, Jun. 1953, p. 52-53 and 74; Gerrits, Russell: "Rod's Beginning”, in: Rod and Custom (R\&C), Jun. 1954, p. 58; Wherry, Joe H.: "Classic Cars from the Vintage Years", in: Car Life (CL), Sep. 1954, p. 52-55; Parks, George A.: "Perpetual Youngsters", in: CL, Dec. 1954, p. 42-45; Hegge, Robert: "Antiques in the Ozarks", in: CL, Mar. 1955, p. 55-58; Greenlee, Lyman: "So You Want to Restore a Classic, Part II", in: Motorsport, Jun.-Jul. 1955, p. 24-25, 46-48 and 50; Warren, Marian: "They Like 'Em Old", in: CL, Jul. 1955, p. 28-31; Anon.: "Restoring an Aristocrat", in: Motor Life (ML), Jan. 1956, p. 50-51; Anon.: "Long Live the A", in: Auto Craftsmen, Dec. 1957, p. 12-13. On restoration and refurbishment, see Schroeder, Bill: "Where the Ages Meet", in: Motorsport, Dec. 1951, p. 1617 and 22-23; Wherry, Joe H.: "Model A Club", in: CL, Aug. 1954, p. 51-54; Bowman, Hank Wieand: "Sutton's Shiny Scraps", in: Auto Age, Oct. 1954, p. 38-39 and 46. From the 1960 s to the present, "restoration" has remained predominant. 
factory - Sennett's "restoration" fits. But to those for whom it can mean "better than new" in some way - thicker sound deadening, improved rustproofing, or even engine and chassis modifications like electronic ignitions, smoother-riding shocks or better-quality tyres or brakes - "remediation" is a closer fit. Among gearheads, a number of more specific terms delineate the finer gradations: "concours restorations", "driver restorations", "sympathetic restorations", "resto mods", and so forth. But the broadest term of art across the hobby's many subgenres is simply "restoration". 12

With all of this in mind, this essay uses the vocabulary of the old-car hobbyist: repair, restoration and (occasionally) refurbishment. ${ }^{13}$ Synonyms, when they creep in, will be clear from the context.

\section{OLD-CAR RESTORATION: A BRIEF SURVEY ${ }^{14}$}

From the 1890 s to the 1920 s, automobiles were seldom "restored". At most they were "refurbished", typically to squeeze a few more years from them or to make them more attractive in the nascent resale market. Among owners, this could mean a thorough tune-up, perhaps some fresh paint and attention to the upholstery, and almost certainly a healthy dose of elbow grease to clean the whole car up. ${ }^{15}$ Among dealers, who began to struggle with a second-hand surplus known

12 There are also many synonyms. "Fix" is often used for "repair", while "fix up" can mean either "restore" or "refurbish", depending on the context. In place of "restored" one will sometimes find "rejuvenated", "reworked", "rebuilt", "renovated", "redone" or, especially but not exclusively among non-native speakers, "renewed" (see Upstream Trading: advertisement, https://www.thesamba.com/vw/classifieds/detail.php? id=2172759 [from a Brazilian firm]; Porsche Kaiser: advertisement, https:// www.thesamba.com/vw/classifieds/detail.php?id=2160769 [from a German individual]; ER Classics: advertisement, https:/www.thesamba.com/vw/classifieds/detail. php?id=2154455 [from a Dutch firm], all accessed 14.08.2018. Also, there are a number of "re-" terms for the various tasks associated with a restoration, including "refinished", "repainted", "resprayed", "retrimmed", "reupholstered" and "rebodied".

13 The same applies to all of the specialist terminology I deploy in this essay: with rare (and clearly marked) exception, it is the language of the old-car hobbyists themselves.

14 This section draws heavily on my recent book: Lucsko, Junkyards, ch. 2.

15 Kilburn, Edwin: "Fitting a Mechanical Lubricator to an Old Car", in: Horseless Age (HA), 20 Mar. 1907, p. 399-400; Teachont, C.: "The Reader's Clearing House”, in: Motor Age (MA), 4 Nov. 1915, p. 38; Anon.: "Editorial Perspectives", in: MA, 7 Mar. 1918, p. 10. 
as the "used-car problem" in the 1910s, refurbishment nearly always involved similar measures, but could also entail far more radical procedures for improved marketability: fitting a new body to turn an old sedan into a speedster, converting a beat-up touring car into a truck, and the like. ${ }^{16}$ Restoration, on the other hand, referred to the process of fixing up an old car not because it was otherwise unattractive or unserviceable, but instead because it possessed sentimental, historic or monetary value. Early on, restoration therefore stood apart from refurbishment less in process than in motivation. Unless an older car was modified extensively while being refurbished, that is, the process of restoring another would have looked much the same: a thorough clean, a tune-up, touch-ups to paint and upholstery, and the like. ${ }^{17}$ But while one car might have been refurbished because its advanced age made it undesirable, another might have been restored because its age actually made it desirable.

At the dawn of the twentieth century, of course, "advanced age" meant something very different when applied to automobiles than it would a few decades later. The car itself was still a new technology at the time, and its fundamentals were evolving rapidly. Thus a three- or four-year-old car might indeed have seemed quite old, functionally and aesthetically. Cars like this, which the press called "ancients" or "relics", could be tough to resell. Some were refurbished by second-hand dealers and thereby found new homes, but often they met different fates. A few were scrapped, although this was uncommon at the time, while others, especially those still owned by wealthy early adopters who had since moved on to more up-to-date designs, were simply "tucked away in private

16 Anon.: "Remaking a 1910 Model", in: MA, 31 May 1917, p. 47; Barnes, Ray A.: "Comments and Queries", in: HA, 28 Jan. 1914, p. 164-165; Anon.: "Putting the Used Car Among Dealer's Assets”, in: HA, 1 Nov. 1917, p. 18-19 and 88. See also Lucsko, Junkyards, ch. 1; Gelber, Steven M.: Horse Trading in the Age of Cars: Men in the Marketplace, Baltimore: Johns Hopkins University Press 2008, ch. 4.

17 Indeed, this is likely why the concept of "refurbishment" survived within the old-car hobby well into the 1950s (see above, footnotes 11-12), and even on occasion to the present: especially in the interwar and immediate post-war years, many of the old cars hobbyists worked on weren't yet quite so old, at least in terms of their condition, to require anything more than what a used-car lot might do to make an unappealing car less so. The same applies from time to time to modern hobbyists working either on the cars of the more recent past (the 1980s, for example) or on uncommonly wellpreserved "survivors". 
stables" and forgotten. ${ }^{18}$ For in the 1890 s and 1900 s, sufficient time had not yet passed for these "ancients" to have become collectible, and thus restorable.

During the 1910s, however, elites on both sides of the pond began to pay attention to them. In 1911, two nobles sponsored an effort to track down early examples for display in a London museum. ${ }^{19}$ In 1913, the organisers of a new-car expo in the US offered a prize to the oldest car that could make it to the show under its own power, ${ }^{20}$ while in 1916 the Haynes Company launched an effort to locate the oldest of its cars still in service. ${ }^{21}$ For its part, the automotive press in Europe and the US began to wax nostalgic about the early days of motoring through retrospectives and celebratory features on surviving "old timers". ${ }^{22}$ Oblique references to do-it-yourself restoration began to crop up here and there in the 1910 s and 1920 s, too. ${ }^{23}$ Bit by bit, an old-car hobby was emerging.

By the 1930s, the new pastime was sufficiently widespread among middleclass Americans ${ }^{24}$ to support the founding of the Antique Automobile Club of America (AACA, 1935) and the Horseless Carriage Club of America (HCCA, 1937). Members of these organisations were chiefly interested in what they called "antiques", vehicles from the 1890s-1910s (HCCA) or the 1890s-1920s

18 Anon.: "What Becomes of Out of Date Cars?", in: HA, 31 May 1905, p. 600 (quote); Anon.: "What Becomes of Old Automobiles", in: MA, 23 Feb. 1928, p. 12; Anon.: "Where the Old Cars Go", in: The Automobile (TA), 20 May 1909, p. 841.

19 Anon.: "England Opens Its Motor Car Museum", in: MA, 27 Jun. 1912, p. 22; Fowler Dixon, W. S.: "John Bull Preserves Early Models of Power Propelled Vehicles By Placing Them in Motor Museum”, in: MA, 2 Apr. 1914, p. 20-21.

20 Anon.: "Pennsylvania's 'Oldest Car'”, in: HA, 28 Jan. 1914, p. 148.

21 Anon.: "From the Four Winds", in: MA, 8 Jun. 1916, p. 47; Anon.: "New Haynes for Old", in: MA, 19 Oct. 1916, p. 24.

22 Anon.: "Ancient History", in: TA, 23 Feb. 1911, p. 539, and 2 Mar. 1911, p. 627; Anon.: "Motoring of Early Days", in: MA, 6 Jun. 1918, p. 5-11; Duryea, Charles E.: "Motor Racing 20 Years Ago", in: MA, 27 May 1915, p. 24-28; Anon.: "The Oldest Car in Service", in: Motor, May 1911, p. 53; Anon.: "Priest Owns Oldest Car in the World", in: MA, 27 Jun. 1912, p. 22-23; Anon.: "10-Year-Old Cadillac Makes Fine Showing in English Test”, in: TA, 6 Nov. 1913, p. 883; Anon.: "A Venerable Ride”, in: Motor, Jul. 1913, p. 79-80; Anon.: "From the Four Winds", in: MA, 12 Aug. 1920, p. 56.

23 See for example Anon.: "Motor Junk Is Sold at Fair", in: MA, 3 Jun. 1915, p. 28; Anon.: "Reviving Old Model Car", in: MA, 27 Apr. 1922, p. 43.

24 My research to date on the period from the 1920s to the 1960s has focused almost exclusively on the restoration hobby in the US. Further work on the UK, continental Europe and Australasia in the coming years will allow me to flesh out the global scope of the early restoration hobby. 
(AACA). ${ }^{25}$ After the Second World War, the hobby broadened to include "classics", the luxurious and powerful makes of the 1920s-1930s: Duesenbergs, Mercedes, Rolls-Royces and the like. By the time old-car restoration hit its stride as a broad-based activity in the late 1950s, a third class had emerged. "Specialinterest autos", as this niche was known, included the mass-market cars of the 1920s-1930s (mostly Fords, Chevrolets and Dodges). ${ }^{26}$ Later, during the 1970 s and 1980s, the special-interest class would expand to incorporate post-war massmarket vehicles, including a variety of imports. ${ }^{27}$ Since then the hobby has grown a bit each year, as more and more cars "age in" (i. e. become "old" - old enough either to qualify for "historic" or "old-timer" status in their jurisdictions or club bylaws or to trigger a sense of nostalgia among those who owned or wished to own them when they were new).

\section{OLD-CAR RESTORATION: METHODS AND MOTIVES}

Every restoration is unique, because every vehicle endures its own mix of circumstances during and after its life on the road. Some have owners who meticulously maintain them, while others have less fastidious custodians. Some quickly rust from winter use on salted roads, while others begin to deteriorate only after they are retired from service (and left to the elements in storage lots, salvage yards or carports and other only half-protected spots). Others experience interior damage from UV exposure, suffer chassis fatigue from potholes and other onand off-road hazards, or accumulate a patchwork of collision repairs. Some survive floods, others fires. A few endure most or all of these things. In short, by

25 Stubenrauch, Bob: The Fun of Old Cars: Collecting and Restoring Antique, Classic and Special Interest Automobiles, New York: Dodd, Mead, and Company 1967, p. 33.

26 These period definitions are based on Jaderquist, Classic Thrill, p. 2-7 and 100-102; Anon.: "How to Restore a $\$ 50.00$ Classic", in: MT, Feb. 1953, p. 54-57; Wherry, "Classic Cars from the Vintage Years"; Gottlieb, Robert J.: "So Who Wants an Old Car?”, in: MT, Nov. 1957, p. 42-43; Duerksen, Menno: "Free Wheeling”, in: C\&P, May 1969, p. 45-46; Cramer, Carl/Duerksen, Menno: "Tool Bag", in: C\&P, Oct. 1969, p. 45; Switzer, Carol L./Duerksen, Menno: “Tool Bag”, in: C\&P, Sep. 1971, p. 68; see also Rae, John B.: The American Automobile: A Brief History, Chicago: University of Chicago Press 1965, p. 217-218. By the 1970s and 1980s, "classic car" had assumed a much broader meaning, see Lucsko, Junkyards, ch. 6.

27 Witness the advent of a Hemmings spin-off in 1970, Special-Interest Autos, which focused on the mass-market makes of the 1920s-1950s. 
the time a car becomes a restoration project, it will have its own particular blend of mechanical, electrical, structural and cosmetic problems.

It can take many years to breathe new life into seized-up engines and corroded relays, and to put right mangled wiring, rotten upholstery and rusted-out bodies. Even matching the colour and sheen of factory paints can be a daunting task in practice, whether due to a dearth of original documentation or to the effects of various regulatory phase-outs of toxic substances over the last few decades. ${ }^{28}$ Each of these types of restoration work deserves its own extended treatment, but for the sake of brevity I will focus here on body damage.

Wooden frames and body supports were used extensively on early cars, such that many antique and classic projects require the replacement of split or rotten components. By the 1970s reproduction wooden parts were available for common cars, like Model Ts. But right up to the present, replacing or repairing these elements has often required extensive fabrication, and thus woodworking skills. ${ }^{29}$ For later all-steel vehicles, body problems come in a variety of forms, notably poorly-repaired collision damage and rust. Addressing both requires stripping the affected areas of paint, filler and active rust to reveal the extent of the damage. This is often done by hand, using elbow grease or an angle grinder, but for larger areas there have long been other options: sandblasting, various home- and shop-use chemical strippers and even full-body-shell acid dipping. ${ }^{30}$

28 On paint chemistry and the challenge of recreating colours and finishes, see Bock, Jürgen: "Handbook Paint Chapter", in: Charter of Turin Handbook, p. 95-115; Tutt, Gundula: Kutschenlack, Asphaltschwarz \& Nitroglanz: Fahrzeuglackierung zwischen 1900 und 1945, Bielefeld: Delius Klasing 2018.

29 On reproduction of wooden elements, see Lester Groff: advertisement, in: Chevy Parts and Cars (CP\&C), May-Jun. 1962, p. 26; Syverson Cabinet Company: advertisement, in: C\&P, Apr. 1971, p. 78. On wooden fabrication, see Brown, Arch: "One Neat Pile of Kindling”, in: C\&P, Feb. 1983, p. 12; Anon.: “They Said It Couldn’t Be Done", in: CP\&C, May-Jun. 1962, p. 27; Anon.: "Rolls Draws the Wrong Crowd", in: C\&SC, Sep. 2018, p. 37.

30 Lehman General Sales Co.: advertisement, in: C\&P, Oct. 1969, p. 22; Tyrell, W. T.: advertisement, in: C\&P, Apr. 1971, p. 48; Auto Strippers and Restorers: advertisement, in: C\&P, Aug. 1974, p. 35; Smith, Everett F.: "Routing Rot", in: C\&P, Jun. 1977, p. 156-159; Baskerville, Gray: "Scritch Takes It All Off”, in: Hot Rod (HRM), Apr. 1975, p. 120, 122 and 124; Bryant, Thos L.: "Sports Car Restoration, Part 2", in: Road and Track (R\&T), Jun. 1983, p. 154D, 156, 160, 162, 166 and 168; Kaho, Todd: "VW Rustoration, Part 2", in: HVW, Jun. 1991, p. 54-56 and 88. See also Erwin, Dan: "Project Junkyard Greyhound", in: European Car (EC), Apr. 2002, p. 102, 104 and 106-107, and Jun. 2002, p. 140 and 142-145. 
Once a car is stripped and the scope of its problems is known, the real work can begin. Bent panels can be beaten back to form with hammers and bucks, while more extensively damaged (or rusted) metal often needs to be replaced. This can be done by drilling out the factory spot-welds, removing the offending panel and welding in a replacement by way of those same spot-weld points, resulting in a very clean repair. Just as often, however, the unsalvageable metal must instead be cut out mid-sheet and its replacement carefully seam-welded into place. ${ }^{31}$ In more extreme cases involving damage to structural elements, temporary braces may need to be tacked in before the offending sections can be addressed safely. It all depends on where the damage happens to be.

Even when cutting and welding are not required, bodywork can be tricky. In theory, bolt-on panels like bonnets and wings can simply be replaced, but in practice the results can be subpar. Sometimes this is due to hidden damage, such as ever-so-slightly bent bodies to which new parts will not neatly fit. Sometimes it is due instead to poor-quality reproductions - bonnets with misaligned boltholes, say - or to the use of parts intended for models sold in other markets (which may look similar but have different mounting points or accessory cutouts). ${ }^{32}$ Because they tend to fit better, original panels sourced from salvage yards have long been favoured. But they haven't always been abundant, especially for antiques and classics. As Rod and Custom put it in 1954, describing the restoration of a 1910 Buick, “[y]ou can't [just] run down to the nearest wrecking yard and buy a fender or two". 33

Why not? Many antiques and classics were never produced in large numbers to begin with, making the long-term survival of more than a handful of salvageyard examples extremely unlikely. Also, many new-car dealers and manufacturers destroyed thousands of "old timers" during the interwar years to remove competing used cars from the market, and thousands more were scrapped for steel during the Second World War and the Korean War. ${ }^{34}$ For the antique or

31 Anon.: "Dog Gone Rust", in: Super Chevy, Jan. 1997, p. 72-73, 75 and 76; Sly, James: "Restoration", in: EC, Dec. 2000, p. 136-145; Erwin, Dan: "Project Junkyard Greyhound", in: EC, Sep. 2002, p. 110 and 112-117.

32 Kirsten, Dean: "VW Fenders 101", in: HVW, Sep. 2002, p. 90-91 and 128.

33 Anon.: "The Past Meets the Present", in: R\&C, Feb. 1954, p. 10.

34 1920s-1930s manufacturer/dealer scrappage: Lucsko, Junkyards, ch. 1; Gelber, Horse Trading, p. 71-72. Second World War: White, John R.: "Hemmings Offers Seed Money to Help Keep the Old-Car Hobby in Bloom”, in: Boston Globe, 4 Sep. 1993, p. 45; Zimring, Carl A.: Cash for Your Trash: Scrap Recycling in America, New Brunswick: Rutgers University Press 2005, ch. 4. Korean War: Mullaney, Thomas E.: "U.S. to Step Up Auto-Graveyard Scrap Flow", in: New York Times, 4 Nov. 1951, 
classic enthusiast of the 1950s, the relative dearth of salvage-yard spares left three options: hiring a specialist to fabricate parts; locating others with similar cars and swapping parts; or finding and buying a "parts car", a wrecked or hopelessly worn-out vehicle used as a rolling source of spares. ${ }^{35}$ The first was out of the question for most budget-minded do-it-yourselfers, while the third grew tougher every year. ${ }^{36}$ This left the second, and by the early 1960 s, swap meets and classified-heavy periodicals like Hemmings (1955) and Cars and Parts (1957) had become vital pillars of the antique- and classic-restoration hobbies.

Others had better luck sourcing spares. This was especially true of the special-interest hobbyists who emerged in the 1950s. Because they favoured the mass-produced cars of the 1920s and 1930s - Fords, Chevrolets and the like, which were abundant in American salvage yards - they had little trouble finding what they needed. ${ }^{37}$ This would remain true for many years, in part because of the sheer number of mass-market cars produced in the 1920s and 1930s, but also because the special-interest niche itself continued to expand. By the 1980s, it included everything from 1940s Fords and 1950s Cadillacs to 1960s muscle cars, and even many post-war imports. Salvaged parts for all of these were plentiful and cheap. ${ }^{38}$

Reproduction parts also trickled into circulation after the Second World War. No full study of the aftermarket restoration business has yet been done, but a preliminary survey suggests that by the early 1960s, a number of firms sold "repro" body panels, engine parts, upholstery, rubber, trim, tyres and other items for common special-interest cars. ${ }^{39}$ Also, enthusiasts with less-common vehicles

p. 143; Anon.: "NPA to Order More Old Cars Scrapped", in: Automotive Industries (AI), 15 Dec. 1951, p. 20; Gottlieb, Robert J.: "Classic Comments", in: MT, Oct. 1953, p. 36-37 and 55.

35 Stratton, "Museum in the Rough", p. 49.

36 Parks, "Perpetual Youngsters", p. 42-45.

37 Wherry, "Model A Club", p. 51-54; Jaderquist, Gene: "Classics and Antiques", in: Motorsport, Nov.-Dec. 1954, p. 33-36; Anon.: "Long Live the A", p. 12-13.

38 Lucsko, Junkyards, chs. 2-3.

39 A few examples from among the many in evidence by the early 1960s: Ford Parts and Supply Company: advertisement, in: Antique Parts and Cars (AP\&C), Jul. 1962, inside cover; Jim Sharman: advertisement, in: AP\&C, Jul. 1962, back cover; Lester Groff advertisement, in: AP\&C, Aug. 1962, inside cover; William Farhy: advertisement, in: AP\&C, Aug. 1962, inside cover; and advertisements from Jim's Auto Parts, L. G. Carlson, Burchill Antique Auto Parts, Max Merritt, Robert E. Darr and Les Leather (all in: AP\&C, Oct. 1963, p. 114). There is no need to further belabour the point: the reproduction-parts business was clearly on its way (though many of these 
sometimes hired workshops to produce batches of scarce components, keeping what they needed and selling the rest to help underwrite the cost. ${ }^{40}$ As the oldcar hobby continued to expand, so did the repro trade. By the early 1980s, extensive portfolios were available for virtually any car one might hope to rebuild, from VWs and Fords to Packards and Bentleys. Even complete bodies were available for several makes - "the single most fantastic thing that has ever happened in the history of the universe", as one gearhead put it when new bodies for 1960s Camaros became available in $2004 .{ }^{41}$ Not all of these aftermarket parts were necessarily high-quality: repro trim, rubber, and interior components, like the aforementioned poorly-fitting body panels, weren't always up to factory form, let alone the better-than-new standard to which many aspired. ${ }^{42}$ Nevertheless, their broad availability made restoration simpler. After all, why bother repairing a cracked engine block, mangled wing or malfunctioning relay when one could just replace them and move on? Why indeed. ${ }^{43}$

simply bear the name of an individual, suggesting origins similar to those detailed in footnote 40).

40 A few examples: Greenland, Sheldon: advertisement, in: C\&P, Oct. 1969, p. 30 ("exact reproductions" of antique brass and other trim parts); Hirsch, Bill: advertisement, in: C\&P, Apr. 1971, p. 41 (a one-time deal for Packard and Continental hubcaps reproduced by the shop that made the originals years earlier); Sommer, Don: advertisement, in: C\&P, Apr. 1971, p. 52 (reproduction 1930-1931 Chevrolet bonnet ornaments). As other cars joined the old-car hobby over time, early efforts to supply parts often came from enthusiasts as well. During the 1980s, for example, when VW Microbuses "aged in" en masse, enthusiasts like Keith Woerle of San Diego began to reproduce small parts such as camper roof-rack clamps (see "Transporter Talk", in: HVW, Oct. 1987, p. 16-17).

41 An early example was the all-steel pre-war roadster body produced by Experi-Metal Inc. of Michigan in the early 1980s (advertisement, in: Street Scene (SS), Sep. 1983, p. 17); by the 2000s, brand-new, all-steel bodies for 1950s Chevrolets, early Camaros and even MGs were available (the MG bodies being factory reproductions sold through MG Heritage). See Bowling, Brad: "Jet Age Revival", in: C\&P, Jan. 2008, p. 16-19; Anon.: "Bench Racing”, in: HRM, Dec. 2004, p. 18 (quote); http://www. bmh-ltd.com/mgbshell.htm (accessed 09.10.2018).

42 See Kimball, Rich: "Need an Original Interior for that '50s Beetle?", in: HVW, Jul. 1996, p. 70-71 and 127.

43 A few examples from earlier times, when many parts had to be rebuilt because replacements weren't available: Deeter, Robert L.: “The Tool Bag”, in: C\&P, Jun. 1977, p. 145 (cracked engine-block repair); Brown, Arch: "Maxwell Model '35'”, in: C\&P, Feb. 1983, p. 22-23 (fabrication of a replacement bonnet); Anon.: "High-Herm", in: HVW, Oct. 1987, p. 74-75 (fabricating replacement interior panels). 
In time, this aftermarket abundance contributed to the rise of "overrestoration", for it allowed one to replace not just what was worn out, but also what was merely worn in. In other words, many finished projects looked and ran like new because they were substantially new. Like Sennett's craftsmen who "remediate", many also availed themselves of improved materials and methods as they strove for perfection - witness Ofner's cad-plated hardware and powdercoated chassis or any of countless others finished with multiple coats of handrubbed base- and clear-coat paint, treated with anti-rust compounds or fitted with better-quality wing beading, more robust upholstery or odometers rebuilt and reset to zero. ${ }^{44}$ Yet apart from the occasional complaint about overwrought replicas, ${ }^{45}$ none of these practices stood out very much in the $1970 \mathrm{~s}, 1980 \mathrm{~s}$ or $1990 \mathrm{~s}$. They were perfectly in sync with the overarching "like-new" mantra.

True of those who aimed for factory originality as well as those who did not mind a tweak or two for drivability, durability or comfort, the old-car world's widespread fixation on pristine newness echoes, at least in part, an important aspect of Sennett's craftsmanship: "the desire to do a job well for its own sake". ${ }^{46}$ What counts as a job well done? Sennett explains that "[i]n the traditional world of the archaic potter or doctor, standards for good work were set by the community, as skills passed down from generation to generation". ${ }^{47}$ Likewise, in the old-car world, the "showroom-new condition" standard was, for many decades and for several generations, simply what one meant by "job well done".

Why? Here one needs to read between the lines. Across the years, an open embrace of all things old has been widespread among restoration hobbyists: parts and supply houses with "obsolete" in their names, magazines with "old" in their titles, car shows at which various aspects of long-bygone pop culture are

44 See above, footnote 1; Alhadeff, Jere: "Full Circle", in: HVW, Nov. 1984, p. 63; Gregory, Fred M. H.: “The \$64,00 Paint Job”, in: C\&D, Jul. 1993, p. 107-108, 110 and 113-114; Smith, Robert K.: "Great Lakes Ghia”, in: HVW, Jul. 1996, p. 102; Id.: "Restored by Ruth”, in: HVW, Dec. 2002, p. 66-69; Cooper Classics: advertisement, in: C\&P, Oct. 1969, p. 7; Anon.: "New Products for Restorers", in: AP\&C, Jul. 1962, p. 35. The use of better upholstery and reset odometers continues to the present; see for example Black Dog 1999: advertisement, https:/www.thesamba.com/vw/classi fieds/detail.php?id=2161196, and CFRI 2899: advertisement, https://www.thesamba. $\mathrm{com} / \mathrm{vw} /$ classifieds/detail.php?id $=2154528$ (both accessed 27.09.2018).

45 See Worthington-Williams, Mike: “Opinion”, in: C\&SC, May 1990, n. p.

46 Sennett, Craftsman, p. 9.

47 Ibid., p. 25. 
carefully recreated through period props and costumes, and so forth. ${ }^{48}$ But not until the recent patination turn did any of this actually mean "old things" as such. Instead it meant old things when they were new. It was a broad nostalgia for the moment an old car left the factory, or when it first hit the showroom, or when it was first parked in the driveway with pride - moments when it represented progress. In a sense, enthusiasts have long cherished old cars made to look and drive like new because they offer tangible connections to those moments. They bring back to life the progress of the past by showing off Ford's cutting edge in 1932, Packard's in 1955 or Porsche's in 1967.

As for all the years since? One's task, in the old-car hobby, was to make it seem as though they had never happened.

\section{THE PATINATION TURN}

Twenty-two years after Ofner's Beetle graced the pages of Hot VWs, a very different sort of car appeared in Octane. This too was an early Volkswagen, and it too had been painstakingly restored. The difference was that this vehicle, a 1952 van, was hardly better-than-new, or even like-new. It had no hubcaps, its seat was bound with duct tape, and most of its exterior was covered in rust. It looked as though no restoration work had ever been attempted, yet its owner, Ben Laughton of Dorset, UK, had worked for several years to get its look and feel just right. Discovered in a Swedish forest, where it had rested on its side for more than fifty years, the van was so fragile with rust that it proved impossible to pull it from the woods without further damaging its brittle bones. Instead, Laughton cut it into several smaller and much more stable sections, piled them on a trailer and headed out of the woods. Once home, he carefully stitched it

48 A few examples of "obsolete" parts houses across the years: the Obsolete Parts Company of Gallup, New Mexico (1970s); Parts Obsolete of Costa Mesa, California (1990s); BFY Obsolete of Orange, California (1990s); Obsolete Buick Parts of Dallas, Texas (2000s); and GM Obsolete of Phoenix, Arizona (2000s). Among periodicals, Old Cars Weekly (U.S.) and Old Autos (Canada) have been published for many years. Regarding pop culture, see for example Janes, J. George: “Antique Antics”, in: Motorsport, Dec. 1954, p. 8-11 and 36; Coleman, Bill: "New England Street Rodders 10th Annual Swap Meet", in: SS, Mar. 1984, p. 30; Anon.: "Life in the Past Lane", in: HRM, Jan. 1990, p. 21; Iola Old Car Show: advertisement, in: C\&P, Apr. 1992, p. 171; the outfits and atmosphere at the UK's annual Goodwood Revival and the US's annual Amelia Island Concours (https://www.goodwood.com/flagship-events/ goodwood-revival and https://www.ameliaconcours.org, both accessed 05.10.2018). 
back together. "Wherever possible", Octane explained, he "saved original panels, although they invariably needed fresh metal letting into the edges". And "[w] here there was simply not enough metal left to save", he "tried to use appropriate-age donor panels", seam-welded and carefully blended with the surrounding metal. After refinishing the chassis and fitting rebuilt running gear, the van was done. It looked like hell, but ran like new - exactly what he wanted. ${ }^{49}$

Laughton's van was not an unfinished project, nor was it a neglected clunker. It was also clearly not a well-preserved original of the sort one often sees at auction. ${ }^{50}$ Instead, like many others owned by twenty-first-century gearheads - vehicles ranging from 1930s-1960s sedans and muscle cars to 1940s-1950s offroaders and delivery vans, as well as countless air-cooled Volkswagens like his own $^{51}$ - Laughton's was a "patina ride". It was rebuilt not to erase but to save its marks and scars, the evidence of all that it had been through since it was new. This may seem reasonable, or even second nature, to anyone familiar with other kinds of collectibles. But in the context of the old-car world, a bit more work remains to better account for cars like this. Why, after seventy-plus years of chasing factory-fresh perfection, did some begin to value wear and tear? Why did glossy finishes and crisp upholstery start to lose ground to faded paint, surface rust and ragged seats? How might we make sense of the old-car hobby's patination turn?

Five related factors figure in. The first was the arrival, in the early 1990 s, of "rat rods". Like the rough-and-tumble, race- and road-going hot rods of the $1930 \mathrm{~s}$ - and decidedly unlike the pristine street rods of the 1970s and 1980s - rat rods, at the outset, were older cars modified for performance and drivability, rather than aesthetics. Also known at first as "beaters", ${ }^{52}$ they were meant to be

49 Dixon, Matt/Laughton, Ben: “The Ultimate Barn (Door) Find”, in: Octane, May 2018, p. 92-100, quote p. 99.

50 Anon.: “To Restore or Not to Restore? That Is the Question”, in: R\&T, Apr. 2007, p. 116. See also above, footnote 4.

51 Examples abound. For instance, Freiburger, David: "Love Your Rust", in: Car Craft (CC), Sep. 2005, p. 10; Smith, Jeff: "The \$3,500 Challenge”, in: CC, Dec. 2006, p. 54-59; Anon.: "Early Landies Go Home for 65 $5^{\text {th", }}$ in: C\&SC, Sep. 2013, p. 21; Davis, Jacob: "Mother Nature's Masterpieces", in: HRM, Sep. 2018, p. 50-52, 54, and 56; Hunkins, Johnny: “The Survivor Phenomenon”, in: CC, Dec. 2018, p. 4; Nalu33: advertisement, https://www.thesamba.com/vw/classifieds/detail.php?id=2176378 (accessed 09.08.2018); 57dbldoorpanel: advertisement, https://www.thesamba.com/vw/ classifieds/detail.php?id=2203357; paul leahy: advertisement, https://www.thesamba. com/vw/classifieds/detail.php?id=2179512 (both accessed 20.08.2018).

52 See Freiburger, David: “Order Rodentia”, in: HRM, Nov. 2010, here p. 45. 
enjoyed, not coddled. Early rat rodders therefore spent the bulk of their time and energy under the bonnet, rather than on paint or upholstery. As a result, their finished projects tended to look rather "ratty", though this was mostly due to benign neglect and not design. Then, over time, this shabby aesthetic assumed a central role in its own right. Consequently, by the early 2000s many rat rodders were spending a considerable amount of time on their vehicles' appearance in a somewhat paradoxical effort, often involving the deliberate cultivation of faded paint and rust, to make it seem as if they did not care about the way they looked - or rather, more precisely, to make it known that they enjoyed their coarse and tarnished look. ${ }^{53}$ And as this counter-aesthetic spread, it helped to pave the way for vehicles like Laughton's: rough and rusty, but ready to roll.

Ready to roll: therein lies the second factor. Simply put, part of the appeal of a patina ride is that it can be enjoyed in ways that other kinds of restored cars cannot. Consider "concours restorations". These are vehicles that have been rebuilt to uncompromising standards of perfection in every interior, exterior and mechanical detail so that they can be displayed at highly-competitive annual events like the Pebble Beach Concours d'Elegance in California or the Concours of Elegance at Hampton Court Palace in the UK. Also known derisively as "trailer queens", concours-level restorations are almost never actually driven. Instead they are carried from show to show in fully-enclosed transporters. "Driver restorations", on the other hand, are very nicely restored old cars that are meant to be enjoyed now and then. Those who own them are not concerned about maintaining concours levels of perfection, but they also aim to keep them as nice as possible. As a result, the occasional use a driver restoration tends to see is fairly gentle - sunny weekend cruising, trips to local shows and historic events and the like - rather than the grind and hazards of a daily commute. On the other hand, those who own old cars with "imperfections", everything from minor dings to heavy patination, can and often do enjoy them every day. ${ }^{54}$

The third factor was that from the 1950s to the 1980s, old-car hobbyists began to spend a lot of time in salvage yards. At first this was largely utilitarian: especially in the 1950s and 1960s, when the restoration aftermarket was in its infancy, boneyards were vital sources of parts. But over time, many gearheads developed an appreciation for salvage yards themselves, and for the rusty hulks within them, that went well beyond utility. Popular magazines played a visible role in this shift. Utilitarian parts-hunting features ran regularly in a number of periodicals in the 1950s and 1960s, but slightly more wistful stories about

53 On rat rods, see Lucsko, Junkyards, ch. 2, and Cross, Machines of Youth, ch. 8.

54 See for example Hunkins, Johnny: “Embrace Imperfection”, in: CC, Jun. 2019, p. 4. 
“junkyards we have known and loved" began to appear in the early 1970s and were common by the middle of the $1980 \mathrm{~s} .{ }^{55}$ By far the most active in this regard was the restoration-oriented Cars and Parts, which ran monthly features on specific old-car yards for more than three decades beginning in the early 1980s. These photo-rich spreads quickly became reader favourites, and other publications across the globe were fast to follow suit. Part of the appeal lay in the details: readers relished the challenge of identifying the mangled cars that appeared and pointing out when and where the magazines themselves had misidentified them. ${ }^{56}$

Equally important, however, was the almost palpable sense of loss their junkyard coverage addressed. For by the 1980 s, due to changes in environmental regulations, zoning laws, insurance requirements and the used-parts market, salvage yards with healthy stocks of old cars were dwindling in number. At the same time, prices for many vintage vehicles were rising to levels unsustainable for the average hobbyist, and safety and environmental regulations often made it difficult to own and drive an older car. With all of this in mind, those old-time wrecks that did remain in salvage yards provided a tangible and, for gearheads, much-needed connection to a golden age of automobility that seemed to be receding more and more each day. "Their sun-faded colors contrast vividly", Car and Driver therefore noted in a wistful story about junked cars back in 1988, with "memories still bright in the mind. Each ... has a story to tell, and no way to tell it". ${ }^{58}$ Ten years later, VW Trends noted in a similar feature that those who venture into salvage yards to see their wrecks up close "often have thoughts on

55 Early, utilitarian coverage: Francisco, Don: "A V-8 in Your Model A", in: HRM, Dec. 1951, p. 10-15, 43, 45, 47-48, 50-51 and 53-54; Phelps, Jack: "Bargains in Horsepower", in: ML, Nov. 1955, p. 26-27 and 66; Francisco, Don: "How to Buy Used Engines", in: CC, Feb. 1957, p. 12-17 and 58-59; Walordy, Alex: "Replacement Parts for Your Car", in: CL, Sep. 1958, p. 32-33 and 60-63. Later, more wistful coverage: Anon.: "Junkyards We Have Known and Loved", in: Special Interest Autos, MayJun. 1971, p. 52-53; Hubit, Gregory: untitled letter, in: C\&P, Apr. 1973, p. 114; Mayall, Joe: "Curbside", in: SS, May 1981, p. 6; Benty, Cam: "The Salvage Yard Maze", in: Popular Hot Rodding, Aug. 1982, p. 76-79; Anon.: "Happy Hunting Grounds", in: C\&D, Jan. 1988, p. 86-87; Smith, Jeff: "Treasure of Sierra Vista", in: HRM, Jun. 1989, p. 135-137. See also Lucsko, Junkyards, chs. 2 and 4.

56 See for example Spitoleri, Tony: “Misidentified Junk!” in: C\&P, Jan. 1982, p. 158; Bostick, Kenneth V.: "Salvage Yard Devotee", in: C\&P, Nov. 1995, p. 167; Smith, Robert E.: "Salvage Yard ID", in: C\&P, Aug. 1997, p. 9.

57 See Lucsko, Junkyards, chs. 3-6.

58 Anon.: "Happy Hunting Grounds", p. 86-87. 
how 'life' may have been for [them] ... 'Where have they been?' 'Who owned them?' and 'How did they get here?",59 By actively connecting their readers' collective nostalgia to the forlorn hulks they found in old-car yards, these stories helped them shed their distaste for the less-than-pristine. ${ }^{60}$

The fourth factor goes back a long way, is less direct and thus requires a bit more exposition. In 1931, a group of preservation experts convened in Greece as the First International Congress of Architects and Technicians of Historic Monuments, resulting in a statement of principles called the Athens Charter. Thirtythree years later, a second congress gathered in Italy to develop a stronger statement, the Venice Charter. Of the latter's sixteen detailed articles, the most germane to our discussion here are numbers 9 and 11. Article 9 declares that restoration work aims, above all, "to preserve and reveal ... aesthetic and historic value". But, as Article 11 clarifies, this does not require a wholesale return to a pristine state. Instead, a proper restoration should preserve the layered history of its subject: "[t]he valid contribution of all periods ... must be respected, since unity of style is not the aim." ${ }^{\prime 1}$ However, not only does this stipulation evade the issue of historical authenticity, as Robert Russell has pointed out, by relativising periodisation; it also ignores the fact that "unity of style" is sometimes "precisely the aim of a particular restoration". ${ }^{62}$ Still, the Venice Charter's influence has been strong, especially among gallery and museum curators, for it gave them a useful set of principles for contemplating accuracy, restoration and overrestoration. ${ }^{63}$ It also inspired those who work with several kinds of historic vehicles to draw up statements of their own: the Barcelona Charter of 2003 (ships), the Riga Charter of 2005 (rail) and, most recently, the Charter of Turin of 2013 (automobiles).

Like the Venice Charter, the Charter of Turin was the work of a group of experts in the field (automotive history and preservation, in this case) who wanted

59 Collazo, Frederick Inocencio: "Volkswagens in the Yard", in: VWT, Feb. 1998, p. 48.

60 Lucsko, Junkyards, chs. 2 and 4.

61 Second International Congress of Architects and Technicians of Historic Monuments, International Council on Monuments and Sites (ICMOS): International Charter for the Conservation and Restoration of Monuments and Sites (Venice Charter), Venice: ICMOS 1964.

62 Russell, Robert: "Abstraction, Authenticity, and the Abolition of Time", in: Hardy, Matthew (ed.): The Venice Charter Revisited: Modernism, Conservation, and Tradition in the $21^{\text {st }}$ Century, Newcastle upon Tyne: Cambridge Scholars Publishing 2008, p. 99-106, here p. 102.

63 See for example Deck, Clara: "Conservation of Big Stuff at the Henry Ford - Past, Present, and Future”, in: Objects Specialty Group Postprints 13 (2006), p. 168-183. 
to develop guidelines for the treatment of authentic artefacts among practitioners (museum professionals and restoration specialists as well as ordinary enthusiasts). Much like the Venice Charter, it never quite nails down what it means by "authenticity". Instead it focuses on "historically coherent states" - a 1975 model-year car as it looked and drove in 1975, for example, or as it looked and drove ten years later, or twenty. Thus the key to a successful restoration - defined as an effort to return a vehicle to a chosen point in time - is preparatory research. Only by examining documents like build sheets, photographs and receipts, and by carefully collecting clues from the vehicle itself, can one be certain of the finished product's historical coherence. Otherwise, one risks mixing periods and ending up with a car in a "disrupted state". Tellingly, the Charter lists among disrupted-state examples those that are "intentionally shown in a superficially neglected and damaged condition on the surface" but which mechanically "have been restored to a good standard or even renovated and tuned". ${ }^{64}$ This fits vehicles like Laughton's well. If taken out of context, though, it does appear to preclude most patina rides from serious consideration among the cognoscenti - after all, they are "disrupted", not "restored". But other sections of the Charter make it clear that vehicles with heavy patination are in fact quite welcome, much more so than over-restored examples "which exaggerate an imaginary mint condition" by "extinguish[ing] every 'annoying' or 'unsightly' trace of age and ... historic substance." 65

To bring us back to the matter at hand, factor four in the old-car hobby's patination turn might best be summed up as a broader shift in attitudes about material authenticity. And although I have thus far found but a single reference to the Venice Charter in the vast array of literature on the old-car hobby, ${ }^{66}$ the fact that

64 Charter of Turin, p. 20-21 (all quoted material in this section appears on these pages).

65 Kohler, Thomas: "Authenticity and Authentic Restoration", in: Charter of Turin Handbook, p. 47 (quote). Passages more friendly to the preservation of patina in the Charter and its accompanying essays can be found on p. 16, 19, 20 and 99-102.

66 Though still incomplete, my survey of the literature has thus far only turned up Strohl, Daniel: "FIVA Enacts Charter of Turin, Establishes Historic Automobiles as Cultural Artifacts", in: Hemmings Classic Car, 14 Feb. 2013, https://www.hemmings.com/ blog/2013/02/14/fiva-enacts-charter-of-turin-establishes-historic-automobiles-ascultural-artifacts (accessed 17.01.2019). The following also warrants note: enthusiast periodicals frequently publish stories on specific museums, but they almost never say anything at all about the preservation practices those museums use. And when the subject of preservation in the museum world does come up, it can be quite contentious; see Hopkins, Kenneth W.: untitled letter, in: C\&P, Sep. 1970, p. 80. 
it helped inspire the Charter of Turin $^{67}$ does at least confirm that it has played a role in this broad shift.

So too has a fifth and final factor: the growing importance of originality within the old-car hobby. For many years, the pursuit of like-new perfection has gone hand-in-hand with the pursuit of factory-correct details. Hence the hobby's passion for nicely-preserved, all-original vehicles, as well as for what gearheads call "new-old-stock" (NOS) components: original replacements that went unsold at the time. Such was the allure of these elusive parts that many spent as much time hunting for them as they did actually working on their cars. ${ }^{68}$ Over time, many came to value the authenticity conferred upon their restorations by the use of NOS parts to such an extent that they began to actively seek out genuine used parts, too, even if they showed some signs of wear. They also started thinking much more carefully before replacing imperfect yet authentic and fully serviceable components. In 1988, for example, long before the first patina ride as such was built, Road and Track's Peter Egan found himself in an unexpected conundrum while contemplating the original aluminium panels on his Lotus Seven project. "The side[s] ... were slightly creased where someone had bent them back out of the way to reweld the frame", he explained, and "[t]here was a small dent in the flat rear-body panel where the nose of another car had no doubt leaned ... to lighten its rear traction in a corner". Nevertheless, Egan decided to keep the racing-scarred originals rather than replace them with unblemished repros. Other fans of vintage sports cars helped him make the call. "I never replace anything I can save", one Jaguar enthusiast explained. "You see those old factory inspector's chalk marks on the back of a dash panel and you realize the whole car is full of English ghosts. If you let them escape, they never come back." So Egan kept the panels, warts and all. ${ }^{69}$ But the resulting car was not a patina ride: he carefully restored the rest of the Lotus and ended up with a very presentable, well-preserved original with its history intact. ${ }^{70}$

In time, as others worked to save their projects' scars, the fever slowly spread, as did the number of rough but serviceable components left "as found". Delicate techniques for preserving (and sometimes faking) patination spread as

67 Charter of Turin, p. 7.

68 Tales of NOS "treasure hunts" began to appear in print at least as far back as the early 1970s, if not earlier. See Lucsko, Junkyards, ch. 4. On authenticity, see Orvell, Miles: The Real Thing: Imitation and Authenticity in American Culture, 1880-1940, Chapel Hill: University of North Carolina Press 1989, and Russell, "Abstraction, Authenticity, and the Abolition of Time".

69 Egan, Peter: "Side Glances", in: R\&T, Nov. 1988, p. 24 (all quotes).

70 Ibid. 
well. ${ }^{71}$ In the 1990 s and early 2000 s, this was most clearly evident among those who built rat rods, for whom the warts themselves were often the entire point. But even hard-core rat-rod fans were well aware that something more was at stake in the decision to preserve a pile of patinated parts than simply finding out how far their "rougher-the-better" mantra could be pushed. At stake, to put it most succinctly, were those tangible connections to the past - those ghosts to which Egan alluded. As Hot Rod's David Freiburger put it in 2007, "patina lends proof of life. It tells a saturated story of age, of history absolutely unrevised". ${ }^{72}$ And this, perhaps more than anything else, was why rough-hewn rides like Laughton's van would soon be all the rage. After all, as many an old-car nut has muttered over the years, "it's only original once". ${ }^{73}$

\section{THE PARADOX OF ORIGINALITY: RESTORATION AS INTERPRETATION}

Or is it? Is a car with painstakingly-preserved patina truly "original" - or at least, any more so than one carefully restored to factory-fresh form? More to the point, can faded paint and worn upholstery really tell a "saturated story" of "history absolutely unrevised?"

On these and other crucial questions, many disagreed with the likes of Egan, Freiburger and Laughton. "[T]urned off by excesses in over-restoration", as Road and Track's Matt DeLorenzo countered in 2009, the " "preservation' ... camp has pushed the pendulum just as far in the opposite direction". "[I]t's beyond me," he continued, "how people can ooh and aah over an all-original wreck. This isn't so much preservation as it is neglect". ${ }^{74}$ In the high-end world

71 Elliott, Kev: "Black and Chrome", in: R\&C, May 2013, p. 14; Bortles, JoAnn: "Aged to Perfection", in: CC, Feb. 2019, p. 26-29; Hunkins, "Embrace Imperfection".

72 Freiburger, David: "Patina", in: HRM, April 2007, p. 61.

73 This common saying eventually became the title for a popular-market book: Lentinello, Richard: It's Only Original Once: Unrestored Classic Cars, Minneapolis, Minnesota: MBI Publishing 2008. For an example of the term in use, see "Patina", forum thread, https://www.thesamba.com/vw/forum/viewtopic.php?t=104480 \&postorder=asc (accessed 03.06.2019).

74 DeLorenzo, Matt: “The Road Ahead”, in: R\&T, Dec. 2009, p. 11. 
of auction houses, museums and concours d'elegance, many share his qualms, and the question of whether to preserve or restore remains hotly contested. ${ }^{75}$

So too in the broader world of do-it-yourselfers. "[Y]ou can restore a car hundreds of times but you can never unrestore it", one gearhead posted to a welltrafficked vintage Volkswagen forum, thesamba.com, in 2005. "Once you paint it the first time, it can't be undone." In a play on MasterCard's famous commercials from the 1990s and early 2000s, another poster agreed: "one week, 3 coats base, two clear, $\$ 5 \mathrm{k}$. 40 years of hard work, personality, and character ... priceless" ${ }^{76}$ Several years later, others on that same site clearly saw things differently. "If I hear another 'they are only original once' justifying a rusted out piece of junk, I will puke", wrote one in 2011. "Bringing such a car back to original via restoration does far more to honor that car", s/he added, because "[a] broke down rust bucket is not 'original', it is just a neglected piece of junk that has nothing to do with how that car ran and looked originally". Another put it more succinctly. "Actually, semantically, the term 'Original Condition' is somewhat misleading: these cars did not roll out from the factory worn out!" 77

Therein lies what we might call the paradox of originality. For while a patinated car may not look the way it did when it was new, it is certainly more "original" than a comprehensively restored example, at least insofar as its panels, paint and upholstery - however rusty, faded and worn - are likely those it came with on day one. At the same time, a restored car may look exactly as it did when it was new, but it is certainly less "original" than a patinated example because many of its parts and all of its paint and upholstery will have been replaced. Perhaps the best way out of this puzzle lies in recognising that "originality" is truly fleeting. In other words, "it's only original once" may well mean exactly that: only once, on day one.

Importantly, this paradox of originality extends to what comes after day one, too. For while it is surely true that an old and patinated car reveals its history in ways that others cannot, the things that it makes known are certainly not "absolutely unrevised". Consider Laughton's van. A tremendous amount of work was involved in rendering it ready for the road - arguably even more than typically

75 See for example Craft, B.: “Roddin' at Random”, in: HRM, Jun. 2011, p. 20; Bremner, Richard: "Left Well Alone, or Barn Again?”, in: C\&SC, Aug. 2011, p. 110-113 and 115; Anon.: "To Restore or Not to Restore".

76 "Patina", forum thread, see footnote 73.

77 "What's Worth More: Restore or Survivor? Here's one Answer", forum thread, https://www.thesamba.com/vw/forum/viewtopic.php? $\mathrm{t}=582701$ \&postorder=asc (accessed 03.06.2019). 
goes into a concours-level restoration. And in performing this necessary work on his VW, Laughton and those who helped him did in fact revise its history. So too with nearly all of the patina rides in service: putting their histories on display requires a "disruption", in the words of the Charter of Turin, or the remediative intervention of a craftsman, in the words of Richard Sennett. Or, perhaps more accurately, it requires an approach to the material reality of a given car not unlike that of an historian working with a body of primary documents. Like any good work of history, it requires synthesis and interpretation.

And, like any good work of history, it is also far more apt than not to prompt a lively debate. This the patination turn has surely done. 
